\title{
UNIVERSIDAD DE LA ADMINISTRACIÓN DEL ESTADO COMO UNIVERSIDAD PÚBLICA: ANÁLISIS CRÍTICO DESDE LOS DIVERSOS USOS DE “LO PÚBLICO”*
}

\section{Pablo Soto Delgado ${ }^{* *}$}

RESUMEN: Este texto analiza el argumento conforme al cual solo las universidades que forman parte de la Administración del Estado pueden ser consideradas públicas. Para ello, se explican diversos posibles usos del concepto de lo público, provenientes desde la Teoría del Derecho, la Teoría Política y la Economía. Se señala que no existe una vinculación necesaria entre la idea de lo público y la configuración, con arreglo al Derecho Administrativo, de las entidades educacionales, por lo cual, es posible que haya instituciones no estatales susceptibles de ser consideradas públicas. En virtud de lo anterior, se descarta como justificación para un eventual trato preferente a algunas universidades la circunstancia de ser controladas por el Estado.

PALABRAS CLAVE: Administración del Estado - derecho público y derecho privado - universidades públicas- universidades estatales - concepto de lo público.

\section{THE UNIVERSITY OF THE ADMINISTRATION UNDERSTOOD AS A SYNonymous of The PUblic University: CRITICAL ANALYSIS FROM THE USES OF "PUBLIC"}

ABSTRACT: This text discusses the argument according to which only universities that are part of the State administration may be considered public. For this, the article explains various possible uses of the concept of public, coming from theory of law, political theory and economics. It is argued that there is no necessary connection between the idea of the

\footnotetext{
* Este texto se ha beneficiado, en su versión preliminar, de los comentarios efectuados por el profesor Carlos Peńa, así como de la discusión con los profesores Sabrina Perret y Eduardo Alcaíno. El autor agradece a todos ellos su invaluable aporte.

Fecha de recepción: 20 de julio de 2015.

Fecha de aceptación: 10 de marzo de 2016.

** Abogado. Profesor de Derecho Administrativo y Doctorando en Derecho, Facultad de Derecho, Universidad Diego Portales, (CHILE). Correo electrónico: pablo.soto@mail.udp.cl
} 
public and the configuration under Administrative Law of educational entities. Therefore, there may exist non-governmental universities that can be considered public. In light of the foregoing, it is discarded, as a justification for a possible preferential treatment to some universities, the circumstance of being controlled by the State.

KEYWORDS: Public Administration - Public and Private Law - Public Universities - State Universities - Concept of the Public

Sumario: Introducción. 1) Usos de lo público. (1.1.) Pluralidad de significados. (1.2.) Lo público y el Derecho. (1.3.) Lo público como espacio de sociabilidad. (1.4.) Lo público, la acción y la razón. (1.5.) Bienes públicos. 2) Lo público y la universidad. (2.1.) Un paso previo: no hay propiedad sobre la universidad de la Administración. (2.2.) Universidad de la Administración como sinónimo de universidad pública. (2.3.) La universidad de la Administración no es necesariamente plural ni produce siempre bienes públicos. (2.4.) Acerca del trato preferente. Conclusiones. Bibliografia citada. Jurisprudencia citada. Normas citadas.

\section{INTRODUCCIÓN}

La provisión de educación universitaria en Chile es efectuada por instituciones cuyas estructuras jurídicas difieren entre sí. En primer término, existen corporaciones de derecho público que forman parte de la Administración del Estado ${ }^{1}$. En segundo lugar, hay universidades que se organizan como corporaciones o fundaciones de derecho privado. Finalmente, existen proveedores de servicios superiores de educación que actúan con la personalidad jurídica de derecho público de la Iglesia Católi$\mathrm{ca}^{2}$. Las entidades del segundo y tercer tipo, son universidades "privadas", que, a su vez, se diferencian entre ellas por la época de constitución y el estatuto que permitió su funcionamiento. En efecto, es posible distinguir, por una parte, instituciones no estatales constituidas hasta el ańo 1981, y

$1 \quad$ Universidad de Tarapacá; Universidad Arturo Prat; Universidad de Antofagasta; Universidad de Atacama; Universidad de La Serena; Universidad de Playa Ancha; Universidad de Valparaíso; Universidad de Santiago de Chile; Universidad Tecnológica Metropolitana; Universidad de Chile; Universidad Metropolitana de Ciencias de la Educación; Universidad de Talca; Universidad del Bío-Bío; Universidad de La Frontera; Universidad de Los Lagos; y Universidad de Magallanes.

2 Acerca del sentido y características, para el Derecho Canónico, de las universidades Católicas, puede verse NúNEEz, Manuel (2007a) "Autonomía y libertad de enseñanza en las universidades con ideario religioso. El caso de las universidades Católicas”. En Núñez, Manuel (coordinador): Las Universidades Católicas. Estudios jurídicos y filosóficos sobre la educación superior Católica. Antofagasta: Ediciones Universitarias Universidad Católica del Norte, pp. 49-76, pp. 56-57. 
por otra, aquellas creadas en virtud de la entrada en vigencia del Decreto con Fuerza de Ley No 1 de 1981 del Ministerio de Educación ${ }^{3}{ }^{4}$. El primer tipo de universidades privadas, junto a todas las estatales, forman parte del Consejo de Rectores ${ }^{5}$. Por vías distintas, en condiciones diversas de acceso, las universidades obtienen recursos fiscales, ya sea porque el Estado costea la demanda -a través de créditos, becas o aportes asociados al rendimiento que los estudiantes obtienen en la prueba de selección universitaria- o, en cambio, financia la oferta -mediante aportes fiscales directos y otros fondos -6 . En el país, los estudiantes universitarios se educan mayoritariamente en instituciones que no son órganos de la Administración del Estado 7 .

Bajo este entorno de heterogeneidad en la prestación educacional universitaria, posibilitada por la regulación sectorial, se ha producido un debate sobre el rol que cabe al Estado en relación con las universidades denominadas "públicas". Una de las cuestiones en discusión, se halla en si estas deben recibir igual trato por parte del Estado que el resto de las

Decreto con Fuerza de Ley No 1 del Ministerio de Educación, de 30 de diciembre de 1980, que fija normas sobre universidades. Publicado en el Diario Oficial el 3 de enero de 1981.

4 Universidad Academia de Humanismo Cristiano; Universidad Adolfo Ibáńez; Universidad Adventista de Chile; Universidad Alberto Hurtado; Universidad Autónoma de Chile; Universidad Bernardo O’Higgins; Universidad Bolivariana; Universidad Católica Silva Henríquez; Universidad Central de Chile; Universidad Chileno Británica de Cultura; Universidad de Aconcagua; Universidad de Arte y Ciencias Sociales, ARCIS; Universidad de Artes, Ciencias y Comunicación, UNIACC; Universidad de Ciencias de la Informática, UCINF; Universidad de las Américas; Universidad de los Andes; Universidad de Viña del Mar; Universidad del Desarrollo; Universidad del Mar; Universidad del Pacífico; Universidad Diego Portales; Universidad Finis Terrae; Universidad Gabriela Mistral; Universidad Iberoamericana de Ciencias y Tecnología, UNICIT; Universidad Internacional SEK; Universidad La Araucana; Universidad La República; Universidad Los Leones (ex Universidad Marítima); Universidad Mayor; Universidad Miguel de Cervantes; Universidad Nacional Andrés Bello; Universidad Pedro de Valdivia; Universidad San Sebastián; Universidad Santo Tomás y Universidad Tecnológica de Chile, Inacap.

5 Se trata de las instituciones denominadas "tradicionales": Pontificia Universidad Católica de Chile; Universidad de Concepción; Pontificia Universidad Católica de Valparaíso; Universidad Técnica Federico Santa María; Universidad Austral de Chile; Universidad Católica del Norte; Universidad Católica del Maule; Universidad Católica de la Santísima Concepción; y Universidad Católica de Temuco. Esta conformación se encuentra contenida en el artículo $8^{\circ}$ del Decreto con Fuerza de Ley № 2 del Ministerio de Educación, de 4 de junio de 1985, que fija el texto coordinado, sistematizado y refundido del Estatuto Orgánico del Consejo de Rectores. Publicado en el Diario Oficial el 21 de enero de 1986.

6 Un minucioso detalle del financiamiento fiscal de la educación superior, desde el punto de vista presupuestario, puede revisarse en Contraloría General de la República (2013) Financiamiento fiscal a la educación superior, 75 pp. Disponible en: http://www.contraloria. cl/NewPortal2/portal2/ShowProperty/BEA\%20Repository/Portal/Bases/Contabilidad/ Universidades_del_Estado/Estudios/2013/1.pdf [fecha de visita 20 de julio de 2015], pp. $15-58$.

7 Las cifras, desglosadas por tipo de institución se encuentran en SERVICIO DE INFORMACIÓN de Educación Superior (2015) Compendio Histórico de Educación Superior. Informe de evolución de la matricula total (1983-2014). Disponible en: http://www.mifuturo.cl/index. php/estudios/estructura-compendio [fecha de visita 20 de julio de 2015]. 
entidades proveedoras de educación terciaria, o bien, merecen un "reconocimiento particular" 8 . La disputa tiene como antecedente la inexistencia de un acuerdo acerca de qué cuenta como educación pública en materia universitaria. Como se sabe, desde el año 2011 el movimiento estudiantil develó la latencia del problema ${ }^{9}$, iniciándose luego de ello el análisis por parte de los especialistas acerca del sentido de lo público en la educación ${ }^{10}$. El tema persistió y en la última elección la actual Presidenta de la República comprometió una reforma educacional para fortalecer la educación pública, otorgando "un trato preferente [a] las universidades de propiedad del Estado"11. En este contexto, en los medios de comunicación se ha suscitado una exposición e intercambio de ideas respecto a la publicidad de la educación universitaria y a la exigencia de trato preferente hacia las entidades estatales ${ }^{12}$.

8 Zolezzi, Juan Manuel; De los Ríos, Danae (2008) “El futuro de las universidades estatales”. En Brunner, José Joaquín; Peña, Carlos (editores): Reforma de la educación superior. Santiago: Universidad Diego Portales, pp. 377-402, pp. 397-400.

9 Véanse, al respecto, Confederación de Estudiantes de Chile (2011) Petitorio, 6 pp. Disponible en: http://www.fepucv.cl/wp-content/uploads/2012/05/Petitorio-CONFECHFinal.pdf [fecha de visita 20 de julio de 2015] y Confederación De Estudiantes de ChiLE (2011b) Convocatoria movilización y paro nacional, $1 \mathrm{p}$. Disponible en: http://confech. wordpress.com/2011/05/03/convocatoria-12-mayo-por-la-recuperacion-de-la-educacionpublica/ [fecha de visita 20 de julio de 2015]. En ambos documentos, se reivindica una "prioridad para las universidades estatales".

10 Véanse, por ejemplo, los artículos publicados en Brunner, José Joaquín; Peña, Carlos (editores) (2011) El conflicto de las Universidades: entre lo público y lo privado. Santiago: Universidad Diego Portales, 460 pp.

11 Bachelet, Michelle (2013) Chile de Todos. Programa de Gobierno 2014-2018, 198 pp. Disponible en: http://michellebachelet.cl/programa/ [fecha de visita 20 de julio de 2015], p. 21 .

12 Pueden revisarse las cartas y columnas de Montes, Fernando; Carbone, Ricardo (2013) "Universidad pública no estatal". En Diario El Mercurio, 12 de septiembre de 2013. Disponible en: http://www.elmercurio.com/blogs/2013/09/12/15178/Universidad-publica-noestatal.aspx [fecha de visita 20 de julio de 2015]; Mayol, Alberto (2013) "Brunner, Peña, Bachelet: la educación y la transmutación de lo público”. En Diario El Mostrador, 17 de diciembre de 2013. Disponible en: http://www.elmostrador.cl/noticias/opinion/2013/12/17/brunner-pena-bachelet-la-educacion-y-la-transmutacion-de-lo-publico/ [fecha de visita 20 de julio de 2015]; Eyzaguirre, Nicolás (2013) “¿Por qué creo en la universidad pública gratuita?”. En Diario El Mercurio, 29 de diciembre de 2013. Disponible en: http://www.elmercurio.com/blogs/2013/12/29/18222/Por-que-creo-en-la-universidadpublica-gratuita.aspx [fecha de visita 20 de julio de 2015]; PeñA, Carlos (2014): "La revolución blanda". En Diario El Mercurio, 5 de enero de 2014. Disponible en: http://www. elmercurio.com/blogs/2014/01/05/18378/La-revolucion-blanda.aspx [fecha de visita 20 de julio de 2015]; PÉrez, Víctor (2014) "Presión por recursos fiscales". En Diario El Mercurio, 31 de enero de 2014. Disponible en: http://www.elmercurio.com/blogs/2014/01/31/19103/ Presion-por-recursos-fiscales.aspx [fecha de visita 20 de julio de 2015]; Martínez Concha, Francisco (2014): "Universidad pública". En Diario El Mercurio, 4 de febrero de 2014. Disponible en: http://www.elmercurio.com/blogs/2014/02/04/19202/Universidad-publica. aspx [fecha de visita 20 de julio de 2015]; PeñA, Carlos (2014) "Lo público y las universidades". En Diario El Mercurio, 20 de marzo de 2014. Disponible en: http://www.elmercurio. com/blogs/2014/03/20/20373/Lo-publico-y-las-universidades.aspx [fecha de visita 20 de 
En el centro de la cuestión está la corrección de la utilización del concepto de lo público para referirse a quienes proveen educación universitaria. La discusión versa sobre si solo son establecimientos públicos de educación superior aquellos que se encuentran orgánicamente -es decir, jurídicamente- vinculados con la Administración del Estado a través de un régimen de Derecho Público, o bien, si puede considerarse pública la educación universitaria provista por personas jurídicas de derecho privado. Este desacuerdo no es trivial, en tanto, se obtienen consecuencias de política pública diversas según la posición adoptada. Así, tomando en cuenta la promesa de fortalecimiento de la educación pública del Gobierno, cuando solo es considerada pública la educación universitaria estatal, las políticas al respecto se centrarían en un único tipo de prestadores. En cambio, si no solo es considerada pública la educación provista por órganos universitarios de la Administración del Estado, las decisiones sectoriales deberían ocuparse también de otros proveedores, a saber, universidades no estatales creadas antes y luego de 1981.

El presente texto pretende intervenir en esta discusión, con las siguientes finalidades, a saber, (i) mostrar distintos usos de lo público que permitan comprender en qué sentido puede ser utilizado por quienes defienden la idea de que la educación universitaria estatal es la única susceptible de ser denominada pública; (ii) descartar la equiparación del uso del concepto de lo público para referirse exclusivamente a los órganos del Estado; (iii) ofrecer una específica aproximación desde lo público a la educación universitaria, y, en fin, (iv) defender la idea de que no existe sustento para la exigencia de trato preferente a las universidades de la Administración del Estado. Para ello, se expondrán algunos usos de lo público, provenientes de la Teoría del Derecho, la Teoría Política y la

julio de 2015]; Mayol, Alberto (2014) "El público espacio en que no está Carlos Peña". En Diario El Mostrador, 24 de Marzo de 2014. Disponible en: http://www.elmostrador. cl/noticias/opinion/2014/03/24/el-publico-espacio-en-que-no-esta-carlos-pena/ [fecha de visita 20 de julio de 2015]; VAlLe, Aldo (2014) "Lo público limita con lo privado". En Diario El Mercurio, 29 de marzo de 2014. Disponible en: http://www.elmercurio.com/ blogs/2014/03/29/20633/Lo-publico-limita-con-lo-privado.aspx [fecha de visita 20 de julio de 2015]; Figueroa, Rodrigo et al. (2014) "Castigo a universidades por no pertenecer al Estado". En Diario El Mercurio, 12 de abril de 2014. Disponible en: http://www.elmercurio.com/blogs/2014/04/12/21006/Castigo-a-universidades-por-no-pertenecer-al-Estado. aspx [fecha de visita 20 de julio de 2015]; Elórtegui, Claudio (2014) “ ¿Trato preferente o justo en educación superior?”. En Diario El Mercurio, 30 de agosto de 2014. Disponible en: http://www.elmercurio.com/blogs/2014/08/30/24792/Trato-preferente-o-justo-eneducacion-superior.aspx [fecha de visita 20 de julio de 2015]; Flores, Arturo et al. (2014) "No es posible hablar de discriminación", en Diario El Mercurio, 8 de noviembre de 2014. Disponible en: http://www.elmercurio.com/blogs/2014/11/08/26698/No-es-posible-hablarde-discriminacion.aspx [fecha de visita 20 de julio de 2015]; y SÁnchez, Ignacio (2014): "El presupuesto sí discrimina". En Diario El Mercurio, 9 de noviembre de 2014. Disponible en: http://www.elmercurio.com/blogs/2014/11/09/26741/El-presupuesto-si-discrimina.aspx [fecha de visita 20 de julio de 2015]. 
Economía (2) y se contrastarán con las ideas acerca de la universidad de la Administración del Estado que merece un trato preferente (3). Se ofrecen, finalmente, las conclusiones obtenidas.

\section{1) USOS DE LO PÚBLICO}

\section{(1.1.) PluRalidad De Significados}

Lo público no es un concepto unívoco. Por ello, Habermas explicó que, para analizarlo, el punto de partida está en la constatación de la falta de claridad y variedad de sus usos. Vale la pena, a este efecto citar, en extenso, lo seńalado por el autor frankfurtiano:

"El uso lingüistico de "público» y "publicidad" denota una variedad de significaciones concurrentes. Proceden de fases históricas diversas $y$, en su sincrónica aplicación a las circunstancias de la sociedad burguesa industrialmente avanzada y social-estatalmente constituida, se prestan a una turbia conexión. Ciertamente parecen permitir esas circunstancias -que se ponen a la defensiva frente al uso lingüistico recibido- una utilización tan confusa como siempre de aquellas palabras, su manipulación terminológica" 13 .

Las personas que emplean este término para referirse a un objeto específico -la educación universitaria, en lo que atañe a este artículo-, a menudo lo utilizan para querer decir cuestiones distintas, incluso sin darse cuenta. La literatura ha efectuado esta constatación, en especial, refiriéndose a la relación de lo público con la categoría de lo privado. En efecto, a pesar de que en conjunto producen una dicotomía idónea para dividir todo lo que sea del caso en dos esferas exhaustivas y recíprocamente exclusivas ${ }^{14}$, cuando se invoca la categoría de lo público en comparación con lo privado, no suelen presentarse consideraciones cuidadosas acerca del significado e implicancias que ello conlleva, aunque el contraste entre ambas nociones es una herramienta analítica poderosa para determinar posibles usos ${ }^{15}$. En esta sección, se revisarán algunos sentidos de lo público para ilustrar la riqueza del término y detectar de qué manera es

13 Habermas, Jürgen (2009) Historia y crítica de la opinión pública. La transformación estructural de la vida pública. Traducción de Antonio Doménech. Barcelona: Gustavo Gili, 352 pp., p. 41.

14 Bоввіо, Norberto (2006) “La gran dicotomía: público/privado”. En Bobbio, Norberto: Estado, gobierno y sociedad: por una teoría general de la política. Traducción de José Fernández Santillán. México: Fondo de Cultura Económica, pp. 11-38, pp. 11-12.

15 Weintraub, Jeff (1997) “The Theory and Politics of the Public/Private Distinction”. En Weintraub, Jeff; Kumar, Krishan (editores): Public and Private in Thought and Practice. Chicago: University of Chicago Press, pp. 1-42, pp. 2-4. 
utilizado por quienes defienden su equivalencia con el ámbito de la organización estatal.

\section{(1.2.) LO PÚBLICO Y EL DERECHO}

Un uso clásico de lo público, se encuentra en la distinción entre derecho público y derecho privado. Fue Ulpiano quien, en las Instituciones, efectuó una distinción que pasaría luego al $\$ 4$ del Título I del Libro I del Corpus Iuris de Justiniano. Allí, el jurista romano sentenció que:

"Dos son los aspectos de este estudio, el público y el privado. Derecho público es el que respecta al estado de la cosa romana; privado, el que pertenece a la utilidad de cada cual"16.

Según este pronunciamiento, se denomina público a aquel derecho que versa acerca de la estructura, actividad, organización y funcionamiento del Estado romano ${ }^{17}$. La distinción, como la cita lo indica claramente, solo hace referencia a dos aspectos a estudiar, sin que se trate de campos opuestos. Al contrario, se trata solo de dos positiones para su estudio ${ }^{18}$, es decir, sendos criterios metodológicos: la perspectiva de la comunidad, o bien, la del individuo ${ }^{19}$. Con todo, cree Bobbio que desde Ulpiano "la pareja de términos público/privado ingresó en la historia del pensamiento político y social de Occidente" 20 , sosteniendo, además, que esa dicotomía permite constatar una situación social en que los miembros de un grupo distinguen entre lo que pertenece a la colectividad, de lo que alude a los miembros específicos. A su juicio, con la aportación romana es posible discernir entre un poder central superior y poderes inferiores o periféricos cuya autonomía depende de aquel. De esta autonomía se deriva la posibilidad de que los sujetos, en el derecho privado, tengan la capacidad de formular acuerdos bilaterales cuya fuerza vinculante reposa, con independencia de la regulación pública, en el principio de reciprocidad ${ }^{21}$.

La dicotomía derecho público/derecho privado se transformó, como reconoce Kelsen, en uno de los principios más fundamentales de la ciencia jurídica moderna ${ }^{22}$. El líder de la Escuela de Viena, sin embargo, fue

\footnotetext{
16 Justiniano (1889) Cuerpo del Derecho Civil Romano. Traducción de Ildefonso García del Corral. Barcelona: Jaime Molinas Editor (t. 1), 980 pp., p. 5.

17 Iglesias, Juan (2007) Derecho Romano: Historia e Instituciones. Barcelona: Ariel, 496 pp., p. 93.

IGLESIAS (2007) 94.

IgLESIAS (2007) 94.

IGLESIAS (2007) 11 .

Bоввіо (2006) 18.

Kelsen, Hans (1951) Teoría general del Estado. Traducción de Luis Legaz Lacambra. México: Editora Nacional S.A., 544 pp., p. 105.
} 
un crítico radical al enfoque dualista para abordar el estudio del derecho $^{23}$, pues, a su juicio, la fundamentación de la distinción era sostenida sobre la base de posiciones contradictorias. Por ello, propuso la superación del dualismo, basándose en que no es posible afirmar un ámbito jurídico -el privado- liberado de la regulación estatal, como se pretende, en tanto, todo el derecho del Estado, incluyendo el privado, se realiza sobre la base del orden jurídico ${ }^{24}$.

Desde esta primera aproximación, puede identificarse una relación entre el poder estatal y lo público. Es público el derecho relativo al Estado, es decir, lo que atañe a su organización, actividad, o bien, las normas que produce, y privado el libre espacio en que los sujetos autónomamente generan arreglos dotados de fuerza jurídica. Hay quien ha visto en este uso una manera liberal-utilitarista de deslindar el Estado del mercado. Conforme a ella, se distingue entre el sector estatal ("governmental"), de aquel no estatal ("nongovernmental”). En este último ámbito, los individuos persiguen sus propios intereses de manera más o menos eficiente, es decir, actúan con racionalidad. Esto caracteriza al mercado. Lo que queda fuera, es el Estado ${ }^{25}$, cuya posibilidad misma de existencia se halla en la articulación del sistema de libre intercambio ${ }^{26}$.

\section{(1.3.) LO PÚBLICO COMO ESPACIO DE SOCIABILIDAD}

Pero existe una manera de entender lo público desde una perspectiva diversa. Según ella, lo público se halla en un espacio de fluida sociabilidad entre desconocidos o casi desconocidos. Lo valioso de la vida pública radica en la convivencia y espontaneidad que surge del intercambio permanente entre individuos y grupos heterogéneos que pueden sostener una coexistencia civilizada ${ }^{27}$. Siguiendo a Scruton, Weintraub afirma que la publicidad en este sentido tiene por objeto hacer la diversidad agradable o al menos manejable. Lo público aquí nada tiene que ver con la acción colectiva, sino que, en cambio, sencillamente en vivir la vida con otros ${ }^{28}$. Es un espacio diferente de las estructuras formales de organización, tales como la burocracia o la empresa (Estado o mercado), y de ámbitos de in-

\footnotetext{
23 Por tratarse de distinciones ideológicas, Kelsen argumentó contra los dualismos entre derecho natural y positivo; derecho público y derecho privado; derecho subjetivo y objetivo; Estado y derecho; entre otras. Al respecto, Kelsen, Hans (1941) La Teoría pura del derecho. Introducción a la problemática cientifica del derecho. Traducción de Jorge Tejerina. Buenos Aires: Losada, 213 pp., pp. 68 y ss.

24 KeLSEN (1951) 120.

25 Weintraub (1997) 8.

26 Jiménez Redondo, Manuel (2002) Modernidad Terminable e interminable: Ensayos sobre democracia y liberalismo. Santiago: Universidad Diego Portales-Universitaria, 212 pp., p. 56.

27 Weintraub (1997) 17.

28 Weintraub (1997) 18.
} 
timidad, como la familia y lo doméstico ${ }^{29}$. Históricamente, este espacio se ha ido modificando, como lo muestra Elias $^{30}$, quien da cuenta de la manera en que, a través de cierta evolución de las costumbres, los hábitos de las personas han transitado desde lo social -público en el sentido que se revisa aquí- hacia lo íntimo. La presión social es un elemento que restringe las actividades que se realizan frente a otros con los cuales se convive. De ahí que lo que fuera público en algún momento deje de serlo porque externamente se constriñe a los sujetos para que se comporten de manera distinta frente a los otros:

"Algo más tarde31, la coacción y la continencia a las que hay que someterse, asi como el miedo, la vergüenza y el disgusto que producen las infracciones, aparecen muy claramente, al menos en la clase alta y en los círculos cortesano-aristocráticos, como una coacción social, como vergüenza y miedo producidos por la presencia de otras personas" 32 .

El dominio de esta concepción de lo público se encuentra en el espacio de la calle, los parques, la plaza, el vecindario, cafés y bares. Su carácter y posibilidades se encuentran influenciados por las formas en que es posible configurar los espacios físicos. Este es el sentido en que, introduciendo su escrito de habilitación, Habermas considera públicas "aquellas organizaciones que, en contraposición a sociedades cerradas, son accesibles a todos; del mismo modo que hablamos de plazas públicas o de casas públicas" 33 . Es la ciudad como urbe, esto es, pensada como forma física de aglomeración, el lugar en que la sociabilidad se lleva a cabo ${ }^{34}$. En contraste con lo que se expondrá en el acápite siguiente, esta concepción de lo público carece de los elementos suficientes para transformar esa urbe en una polis.

Ahora bien, se ha sostenido que este uso de lo público al considerar la existencia de otros en un espacio de sociabilidad, dota de visibilidad a la conducta de los individuos ${ }^{35}$. Surge aquí la diferencia entre aquello que es manifiesto, por una parte, de aquello que es secreto, por otra. Sobre la base de esta perspectiva, Garzón Valdés, en un conocido texto, ha escrito que lo público se encuentra "caracterizado por la libre accesibilidad de

\footnotetext{
29 Rabotnikof, Nora (1998) “Público-Privado”. Debate feminista, Año 9, Vol. 18, pp. 3-13, p. 8.

30 Elias, Norbert (1989) El proceso de la civilización. Investigaciones sociogenéticas y psicogenéticas. Traducción de Ramón García Cotarelo. México: Fondo de Cultura Económica, 581 pp., pp. 170 y ss.

31 La revisión documental que efectúa Norbert Elias abarca entre los siglos XV a XVIII. Elias (1989) 176.

Habermas (2009) 41. El original sin cursivas.

Weintraub (1997) 23 y 26.

RABOTNIKOF (1998) 4.
} 
los comportamientos y decisiones de las personas en sociedad"36. Es entonces cuando adquiere sentido su afirmación posterior de acuerdo con la cual, "[s]i lo íntimo estaba caracterizado por su total opacidad, lo que caracteriza a lo público es la transparencia" 37 . Lo opuesto a lo público social se convertirá, ya se sabe, en lo que Warren y Brandeis denominaron, siguiendo al juez Cooley, el derecho a "ser dejado solo"38 como una de las manifestaciones del derecho a la privacidad.

\section{(1.4.) LO PÚBLICO, LA ACCIÓN Y LA RAZÓN}

Hay una tercera noción de lo público, referida a la comunidad política y basada en el concepto de ciudadanía, es decir, en la pertenencia a aquella bajo específicas condiciones. El ámbito de lo público, y la vida que allí se produce es un proceso de participación activa, en un marco de solidaridad e igualdad. Lo público es equivalente, de acuerdo a esta concepción, a lo político; un mundo de discusión, debate, deliberación, toma de decisiones y acción concertada ${ }^{39}$.

Hannah Arendt defendió una poderosa idea acerca de lo público en estos términos. En su Vita activa ${ }^{40}$, designó tres actividades fundamentales correspondientes, respectivamente, a las condiciones básicas bajo las cuales la vida humana se desenvuelve. Con la labor, se refirió a la actividad biológica del cuerpo humano, ligada a las necesidades vitales, cuya condición básica es la vida misma. El trabajo es una actividad no natural. Mediante esta, el ser humano elabora un mundo de cosas artificiales en la condición humana de la mundanidad. En fin, la acción, como tercera actividad fundamental, es la política, que se lleva a cabo bajo la condición humana de la pluralidad, esto es, entre humanos, sin que medien cosas o materia entre ellos ${ }^{41}$. La pluralidad es la conditio per quam de toda vida

36 Garzón Valdés, Ernesto (1998) “Privacidad y publicidad”. Doxa, N² 21, Vol. 1, pp. 223244 , p. 227.

37 Garzón Valdés (1998) 228.

$38 \quad$ La cita es la siguiente: "Recent inventions and business methods call attention to the next step which must be taken for the protection of the person, and for securing to the individual what Judge Cooley calls the right 'to be let alone"”. Véase Warren, Samuel; Brandeis, Louis (1980) “The Right to Privacy". Harvard Law Review, Vol. 4, N 5, pp. 193-220, p. 195.

39 Weintraub (1997) 10.

40 Arendt, Hannah (2005) La condición humana. Traducción de Ramón Gil Novales. Barcelona: Paidós, 368 pp.

41 Como se aprecia, Hannah Arendt coincide aquí, al menos parcialmente, con el concepto de acción weberiano, al menos en el sentido de descartar que sea acción social aquella que se orienta bajo la expectativa de obtener reacciones de objetos. En palabras de Weber, "2. No toda clase de acción -incluso de acción externa- es "social" en el sentido aquí admitido. Por lo pronto no lo es la acción exterior cuando solo se orienta por la expectativa de determinadas reacciones de objetos materiales. La conducta íntima es acción social solo cuando está 
política ${ }^{42}$. A juicio de Arendt, solo la acción es prerrogativa del hombre de modo exclusivo, "ni una bestia ni un dios son capaces de ella, y solo ésta depende por entero de la constante presencia de los demás" ${ }^{43}$. En una lectura del zôon politikon, la teórica política considera que esa definición aristotélica del hombre, se hace operativa en oposición directa a considerarlo como apto para asociarse naturalmente, cuestión que se experimenta en el ámbito familiar. En efecto, el hombre no es un animal social. Al contrario, lo que le resulta propio es ser político, esto es, se encuentra dotado de "una forma de vida en la que el discurso y solo este (tiene) sentido y donde la preocupación primera de los ciudadanos (es) hablar entre ellos" ${ }^{4}$. Esto permite distinguir la esfera pública de la privada: acá lo político -la esfera de la polis-, allá la familia.

Esa delimitación permite plantear una caracterización precisa de dos esferas: la doméstica por una parte, y la de la polis, por otra. En efecto, en aquella, los seres humanos viven juntos, pues, sus necesidades así lo exigen. Aquí, la fuerza que une a los hombres es el mantenimiento individual y la supervivencia de la especie, es decir, la propia vida. Por ello, la necesidad es la causa eficiente y final de la familia, que constituye el ámbito de lo privado. Al contrario, la polis era para Arendt el lugar en que la libertad se localizaba de manera exclusiva y se diferenciaba de la familia -lo privado o doméstico- porque en ella solo había iguales. De ahí que "[s] er libre significaba no estar sometido a la necesidad de la vida ni bajo el mando de alguien y no mandar sobre nadie, es decir, ni gobernar ni ser gobernado" 45 .

Conforme a las ideas arendtianas, es posible diferenciar lo social de lo político. Esto se debe a que, si bien en ambas esferas los humanos se relacionan con otros, en el primer ámbito impera la necesidad, mientras que, en el segundo, lo hace la libertad como igualdad. Con Maquiavelo, Arendt se permite afirmar que en esta distinción se aprecia el tránsito de la esfera privada a la principesca: el camino desde las circunstancias que resultan comunes a todos los hombres (la necesidad de la vida biológica, como se señaló), hacia "la resplandeciente gloria de las grandes acciones" ${ }^{46}$. Esto implica una especial valoración negativa de lo privado,

orientada por las acciones de otros”. Véase Weber, Max (2002) Economía y sociedad. Traducción de José Medina Echavarría. Madrid: Fondo de Cultura Económica, 1245 pp., p.18. Arendt (2005) 35.

43 Arendt (2005) 51. Esta es una forma inversa de presentar la clásica cita de la Politica de Aristóteles (1253a), de acuerdo con la cual "el que no puede vivir en sociedad, o no necesita nada por su propia suficiencia, no es miembro de la ciudad, sino una bestia o un dios". Aristóteles (1989) Politica. Traducción de Julián Marías y María Araujo Fernández. Madrid: Centro de Estudios Constitucionales, 283 pp., p. 4.

44 Arendt (2005) 54.

45 ARENDT (2005) 57.

46 Arendt (2005) 60. 
que según sus términos literales, "significaba el estado de hallarse desprovisto de algo, incluso de las más elevadas y humanas capacidades. Un hombre que solo viviera su vida privada, a quien, igual que el esclavo, no se le permitiera entrar en la esfera pública, o que, a semejanza del bárbaro, no hubiera elegido establecer tal esfera, no era plenamente humano" ${ }^{4}$.

La esfera pública, en la configuración proporcionada en "la condición humana", hace referencia a dos fenómenos diversos, aunque relacionados. En primer lugar, significa que en ella todo el mundo puede ver y oír lo que allí acontece, cuestión que aporta a la certeza sobre la realidad del mundo y la de cada cual. La esfera pública designa también, en segundo lugar, al propio mundo que es común a todos. Teniendo esto en consideración, y con la mayor agudeza, Hannah Arendt se encarga de explicar "el significado de la vida pública", cuya característica es la diversidad de puntos de vistas acerca del mundo en común ${ }^{48}$. Es relevante anotar aquí que el hombre en lo público se inserta en una forma de vida en la que solo el discurso tiene sentido, donde la preocupación primera de los ciudadanos es hablar entre ellos ${ }^{49}$ acerca de las cuestiones comunes. Habermas aclara que el consenso logrado en este intercambio comunicativo, produce poder político. En lo público, los sujetos se ponen de acuerdo sobre una acción común, en un régimen comunicativo sin coacciones ${ }^{50}$. El modelo arendtiano de lo público, entonces, es deliberativo, siendo esta una concepción que Jiménez Redondo explica como sigue:

"Las decisiones tomadas asi en el medio de la deliberación, en el medio de una disputa entre oradores, que se nutre también de la formación argumentativa de la opinión y de la voluntad en el ágora, son tales que tienen a su favor la presunción de contar con buenos argumentos; quienes las han tomado, que son los mismos que van a quedar sometidos a ellas, pueden entender que les han podido prestar su asentimiento en el medio de deliberaciones racionales, es decir, organizadas de forma que el resultado de ella tiene a su favor la presunción de contar con los mejores argumentos" 51 .

Si en lo público entendido de esta forma, la herramienta con que cuentan los seres humanos es el discurso sin coacciones, ello significa que

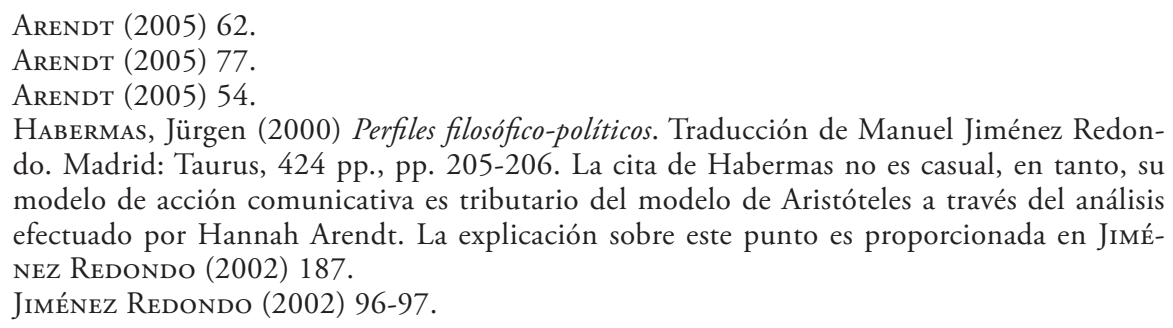


debe existir un uso de la razón que allí pueda operar libremente. Esto es a lo que modernamente Kant denominó razón pública. El sabio de Königsberg, respondiendo la pregunta por la Ilustración, instó a la humanidad a pensar sirviéndose de la propia razón, para que ella se emancipara de los tutores. Es la indicación de una máxima subjetiva de acción dirigida al individuo: que piense por sí mismo ${ }^{52}$. No se requiere, para ello, otra cosa que un tipo de libertad, "la más inocente entre todas" 53 : la de hacer uso público de la razón íntegramente. Este uso debe estar permitido a todo el mundo, y es definido en contraste con el uso privado de la razón:

"Entiendo por uso público aquel que, en calidad de maestro, se puede hacer de la propia razón ante el gran público del mundo de lectores. Por uso privado entiendo que ese mismo personaje puede hacer en su calidad de funcionario" 54 .

Quien ejerce su razón pública no atiende límites, a diferencia del funcionario que, jerárquica y normativamente, se encuentra constreñido a actuar institucionalmente, por lo que posee un tipo confinado de libertad. El que hace un uso público de la razón, se halla dotado de una libertad ilimitada para hablar en nombre propio y servirse de su propia razón ${ }^{55}$. Kant es plenamente consciente de las implicancias políticas del uso público de la razón, pues, este incluye la crítica a la regulación estatal. Por ello, intentando persuadir acerca de las bondades de tal ejercicio cuando son promovidas por el gobernante, señala que "tampoco en lo que respecta a la legislación hay peligro porque los súbditos hagan uso público de su razón, y expongan libremente al mundo sus ideas sobre una mejor disposición de aquella, haciendo una franca crítica de lo existente (...)"56.

Lo público arendtiano y kantiano son cuestiones que se complementan, en la medida que en esta esfera de la pluralidad, cada cual se encuentra en condiciones de enfrentar críticamente su entorno, lo que se concreta a través de la acción común orientada al entendimiento. Por ello es que el uso público de la razón no es un saber de expertos: "[n]o solo en la república de los sabios se realiza la publicidad, sino en el uso público de la razón, ejercido por todos aquellos que acierten ese uso" 57 .

Habermas (2009) 137.

Kant, Emmanuel (2002) “¿Qué es la Ilustración?”. En Kant, Emmanuel, Filosofía de la historia. Traducción de Eugenio Ímaz. México: Fondo de Cultura Económica, pp. 25-37, p. 28.

KANT (2002) 28.

KANT (2002) 31.

Kant (2002) 36. En cursivas el original.

Habermas (2009) 139. 


\section{(1.5.) BIENES PÚBLICOS}

Un cuarto posible uso de lo público, ha sido propuesto por la literatura económica. Paul Samuelson, en un breve artículo de 1954, referido al gasto público, explicaba que es posible constatar la existencia de dos categorías de bienes: bienes ordinarios de consumo privado, por una parte $\mathrm{y}$, por otra, bienes de consumo público colectivo ${ }^{58}$. Los primeros, pueden ser definidos como aquellos cuya cantidad total puede ser repartida entre dos o más personas. Si una de ellas consume más de uno de estos bienes, la otra necesariamente consumirá menos. Al segundo tipo de bienes, en cambio, cada persona puede acceder. Es lo que acontece, por ejemplo, con la seguridad nacional ${ }^{59}$. Si los bienes públicos se incrementan en una sociedad, simultáneamente ello implica un aumento para cada una de las personas $^{60}$. Los bienes públicos se caracterizan por la no rivalidad y la no exclusión. Que no sean rivales significa que ellos pueden consumirse por cualquier número de personas sin agotarse, como acontece, por ejemplo, con el conocimiento. Por su parte, los bienes no son excluyentes cuando los beneficios que generan no quedan limitados en compradores individuales. Así sucede con la tolerancia, el derecho o el orden ${ }^{61}$.

Diferenciándolos de los privados, John Rawls explica que es posible identificar tres aspectos definitorios en los bienes públicos, a saber, que son indivisibles, su carácter público y que en su producción no puede intervenir el mercado, sino que se trata de una decisión política implementada a través de la legislación. Escribió Rawls en 1971:

"La (...) idea fundamental es la de que un bien público tiene dos rasgos característicos, su indivisibilidad y su carácter público. Es decir, hay muchos individuos, un público por asi decirlo, que quiere más o menos de este bien, pero si todos han de disfrutarlo, ha de ser en la misma proporción. La cantidad resultante no puede dividirse, como ocurre con los bienes privados, ni ser adquirida por los individuos de acuerdo con sus preferencias. Hay varias clases de bienes públicos, dependiendo de su grado de indivisibilidad y de su importancia pública. El caso extremo de un bien público es su plena indivisibilidad entre toda la sociedad. Un ejemplo típico es el de la defensa de una nación contra un ataque (injustificado) del extranjero. Todos los ciudadanos deben participar de este bien en el mismo grado; no pueden recibir una protección variada, dependiente

58 Samuelson, Paul A. (1954) "The Pure Theory of Public Expenditure". The Review of Economics and Statistics, Vol. 36, No 4, pp. 387-389, p. 387.

59 Samuelson, Paul A. (1955) "Diagrammatic Exposition of a Theory of Public Expenditure". The Review of Economics and Statistics, Vol. 37, No 4, pp. 350-356, p. 350.

60 Samuelson (1955) 351.

61 Marginson, Simon (2011) "Higher Education and Public Good". Higher Education Quarterly, Vol. 65, N 4, pp. 411-433, p. 415. 
de sus deseos. La consecuencia de la indivisibilidad y de la publicidad, en estos casos, es que la provisión de bienes públicos debe ser estructurada a través del proceso politico y no a través del mercado. Tanto la cantidad que ha de producirse como su financiación han de ser elaboradas por la legislación" 62 .

La teoría de los bienes públicos puede relacionarse con la educación universitaria. Para explicar de qué modo esto sucede, es necesario indicar preliminarmente que el término "bienes" se utiliza de modo genérico para aludir a toda la producción, incluyendo beneficios intangibles o no corporales, tales como los servicios educacionales ${ }^{63}$. El tipo de bienes producidos por las universidades es susceptible de denominarse público. Así acontece con la investigación, bien público que permite, a su vez, la producción de otros bienes públicos y privados. El alto crecimiento de publicaciones disponibles en internet acredita lo anterior ${ }^{64}$. Lo propio sucede con la enseñanza y el aprendizaje, cuyos aspectos de bien público son: el conocimiento aprendido; la contribución a una base de conocimiento compartido; la existencia de un beneficio ciudadano a acceder a la cultura común y a oportunidades sociales; y la contribución de la educación superior a la tolerancia social y al entendimiento internacional ${ }^{65}$.

\section{2) LO PÚBLICO Y LA UNIVERSIDAD}

\section{(2.1.) UN PASO PREVIO: NO HAY PROPIEDAD SOBRE LA UNIVERSIDAD DE LA ADMINISTRACIÓN}

Revisados estos cuatro sentidos de lo público cabe, en este apartado, analizar el argumento conforme al cual solo puede denominarse pública aquella universidad que forma parte de los cuadros orgánicos de la Ad-

62 Rawls, John (2002) Teoría de la Justicia. Traducción de María Dolores González Soler. México: Fondo de Cultura Económica, 549 pp., p. 251.

63 Marginson (2011) 415.

64 Marginson (2011) 425.

65 Marginson (2011) 426. No sin cuestionamientos, se afirma que la educación produce bienes comunes, puesto que, al mismo tiempo, distribuye beneficios meramente privados. Así, Atria, Fernando; Sanhueza, Claudia (2013) Propuesta de Gratuidad para la Educación Superior Chilena. Santiago: Instituto de Políticas Públicas UDP, 15 pp. Disponible en: http:// www.politicaspublicas.udp.cl/publicaciones/detalle.tpl?id=375 [fecha de visita 20 de julio de 2015], p. 6, han sostenido que "hoy tendemos a entender las universidades como 'fábricas de profesionales' cuya función principal es producir un bien de apropiación privada (la calificación profesional) que se justifica porque resultará lucrativo para quien lo reciba”. Recientemente, se ha afirmado que la concepción de lo público entendido como bienes públicos es "intrínsecamente neoliberal" y "una negación de lo público". Sobre esto último, Atria, Fernando (2014) Derechos sociales y educación. Santiago: LOM Ediciones, 332 pp., pp. 227 y 229. 
ministración del Estado. Desde un punto de vista estrictamente técnico, debe corregirse la idea de que la discusión verse acerca de la propiedad de las universidades, por cuanto, el Estado en ningún caso es titular de este derecho sobre ellas. En lugar de ello, las universidades estatales son servicios públicos descentralizados, lo cual significa, conforme al artículo 29 inciso final de la Ley Orgánica Constitucional de Bases Generales de la Administración del Estado ${ }^{66}$ (LOCBGAE), que se encuentran dotados de personalidad jurídica y patrimonio propios asignados por la ley, quedando sometidos a la supervigilancia del Presidente de la República a través del Ministerio respectivo. La doctrina administrativista nacional confirma esta idea, subsumiendo a las universidades estatales bajo la forma jurídica de servicios descentralizados ${ }^{67}$ del Ministerio de Educación ${ }^{68}$, cuestión que ha sido reafirmada por la Contraloría General de la República al menos desde $1990^{69}$. Al respecto, el Ente Contralor ha dictaminado "que, tal como lo ha precisado la jurisprudencia administrativa de este Organismo Contralor (...) las universidades estatales son corporaciones autónomas de derecho público, con personalidad jurídica y patrimonio propios y constituyen servicios públicos integrantes de la administración descentralizada del Estado, plenamente afectos, por ende, a la ley $\mathrm{N}^{\circ} 18.575$, Orgánica Constitucional de Bases Generales de la Administración del Estado"70.

Jurídicamente, las universidades estatales son un "órgano o servicio público creado para el cumplimiento de la función administrativa”, conforme al artículo $1^{\circ}$ de la LOCBGAE. El Consejo para la Transparencia ${ }^{71}$ y el Tribunal Constitucional han resuelto en el mismo sentido. Este último órgano, decidiendo un requerimiento de inaplicabilidad presentado

66 Decreto con Fuerza de Ley No 1-19.653 del Ministerio Secretaría General de la Presidencia, de 13 de diciembre de 2000. Publicado en el Diario Oficial el 17 de noviembre de 2001, que fija texto refundido, coordinado y sistematizado de la Ley No 18.575, Orgánica Constitucional de Bases Generales de la Administración del Estado.

67 Soтo Kloss, Eduardo (2012) "Las personas jurídicas administrativas del Estado". En Soto Kloss, Eduardo: Derecho Administrativo Temas Fundamentales. Santiago: Abeledo Perrot, pp. 255-264, p. 258.

68 Boloña, Germán (2008) Organización Administrativa. Santiago: LexisNexis, 417 pp., pp. 265 y 314.

69 Dictamen No 20.393 de 18 de julio de 1990. Para una crítica a esta "perspectiva administrativa", que se opone a la "perspectiva académica”, en tanto disminuiría la autonomía de las universidades estatales, véase León, José Julio (2011) “El conflicto de las facultades desde una perspectiva jurídica: lo público y lo privado en el debate sobre la autonomía universitaria”. En Brunner, José Joaquín; Peńa, Carlos (editores): El conflicto de las universidades: entre lo público y lo privado. Santiago: Universidad Diego Portales, pp. 299-330, pp. 325-329.

$70 \quad$ Dictamen No 59.048 de 27 de diciembre de 2007.

71 Pueden revisarse, entre otras, las siguientes decisiones del Consejo para la Transparencia: $\mathrm{N}^{\circ}$ C533-09; C38-10; C229-10; C369-10; A229-09; C517-09; C534-09; Rol N C540-09; R1-09; y C449-10. 
por la Universidad de Chile con el objeto de que no rigiera para ella la Ley No 20.285 sobre transparencia de la función pública, señaló:

"CUARTO: Que, asumida esta identidad de la Universidad de Chile, como institución estatal con personalidad jurídica propia de derecho público, entonces su más elemental aplicación es que necesariamente debe subsumirse en algunas de las clases genéricas con que la Constitución concibe al Estado. E integrar, por tanto, su Administración, habida cuenta que no cabe enmarcarla en el Poder Judicial ni en el Congreso Nacional, ni ha sido incorporada expresamente en el texto supremo en una categoría diferenciada, al modo del Ministerio Público o del Tribunal Constitucional.

Siendo de agregar que la unanimidad de la jurisprudencia y la doctrina, reconocen a la Universidad de Chile como un servicio público descentralizado correspondiente a la Administración del Estado;

"QUINTO: Que en esta sede, pues, no procede sino afirmar esa premisa que representa el punto de partida aceptado por la jurisprudencia constitucional, cual es que la Universidad de Chile, al igual que las otras universidades estatales, se perfila con todos los rasgos peculiares y distintivos que caracterizan a los servicios públicos de la Administración del Estado" 72 .

La función administrativa consiste aquí en un deber jurídico de proveer educación, que se encuentra establecido, por expresa voluntad del legislador, en los estatutos orgánicos que rigen la actuación de las instituciones universitarias. Esto es algo muy distinto de la relación jurídica que genera la propiedad, de modo que no es correcto describir el debate como un problema de instituciones "cuyo dominio pertenece al Estado"73. Entonces, el sentido de la aseveración conforme a la cual solo son públicas las universidades del Estado, debe reformularse de la siguiente manera: solo son públicas aquellas instituciones de educación universitaria que forman parte de la Administración del Estado.

72 Tribunal Constitucional. 5 de septiembre de 2006. Rol No 1892-2011. "Requerimiento de inaplicabilidad por inconstitucionalidad presentado por Víctor Pérez Vera, Rector de la Universidad de Chile, respecto de la parte final del inciso primero del artículo $2^{\circ}$ de la Ley 20.285 en el recurso de queja de que conoce la Corte Suprema, bajo el Rol № 9777-2010”. Disponible en: http://www.tribunalconstitucional.cl/wp/ver.php?id=2231 [fecha de visita 20 de julio de 2015], p. 18.

73 Garrido, Juan Manuel; Herrera, Hugo Eduardo; Svensson, Manfred (2012) La excepción universitaria. Reflexiones sobre la educación superior chilena. Santiago: Universidad Diego Portales, 107 pp., p. 63. El original sin cursivas. 


\section{(2.2.) UNIVERSIDAD DE LA ADMINISTRACIÓN COMO SINÓNIMO DE UNIVERSIDAD PÚBLICA}

Con la delimitación recién presentada, cuando se sostiene que solo las universidades de la Administración del Estado merecen ser consideradas públicas, se utiliza al parecer una específica manera de entender lo público, correspondiente al primero de los sentidos revisados en la sección anterior, esto es, aquel que se refiere a la estructura, actividad, organización y funcionamiento del Estado. Desde esta perspectiva, la universidad es pública porque forma parte de la estructura orgánica del Estado, actúa aplicando normas de Derecho Público, y se encuentra constituida de acuerdo al Derecho Administrativo. Una reconstrucción racional del argumento podría ser tentativamente la siguiente:

(i) son públicas las instituciones reguladas por el Derecho del Estado;

(ii) son públicas, también, las actividades (actos y normas) que los órganos estatales realizan;

(iii) cuando una universidad forma parte de los cuadros orgánicos de la Administración del Estado es una universidad pública.

Este uso de lo público es adecuado para aludir a las universidades chilenas que han sido creadas por ley, o bien, se desmembraron regionalmente desde la Universidad de Chile ${ }^{74}$. En tales casos, la calificación a ellas como públicas significa, necesariamente, destacar su característica de formar parte del Estado. Este criterio es el mismo que ha utilizado la OCDE, aunque para efectos estadísticos, encasillando como públicas aquellas instituciones educacionales cuyo control en definitiva descansa en una autoridad o agencia pública de educación, o bien, es gobernada por un cuerpo cuya mayoría de miembros son nombrados por la autoridad pública ${ }^{75}$.

Es difícil estar técnicamente en desacuerdo con este uso de lo público. Si la discrepancia versara sobre la vinculación con la Administración, el debate tendría una solución nada compleja. Al contrario, bastaría con revisar la legalidad vigente, comprender que efectivamente las universidades del Estado son públicas sobre la base del Derecho (Público) vigente y

74 Conforme al Decreto Ley No 3.541 del Ministerio de Educación Pública, de 12 de diciembre de 1980, que delega facultades que indica. Publicado en el Diario Oficial el 13 de diciembre de 1980. Y al Decreto con Fuerza de Ley N ${ }^{\circ} 2$ del Ministerio de Educación, de 30 de diciembre de 1980, que fija normas sobre universidades. Publicado en el Diario Oficial el 7 de enero de 1981.

75 Organisation for Economic Co-operation and Development (2004) OECD Handbook for Internationally Comparative Education Statistics: Concepts, Standards, Definitions and Classifications. Paris: OECD, 271 pp., p. 58. 
dejar de discutir. A menos que sean otros los sentidos de lo público esgrimidos cuando se señala que la universidad pública es solo la estatal.

\section{(2.3.) LA UNIVERSIDAd DE LA AdMINistración NO ES NECESARIAMENTE PLURAL NI PRODUCE SIEMPRE BIENES PÚBLICOS $^{76}$}

Sin embargo, es posible presentar -y rebatir- una versión más robusta del argumento. Los defensores de la idea según la cual solo la universidad estatal merece ser considerada pública quizá quieren significar que solo de las instituciones administrativas de educación superior puede afirmarse que satisfacen los sentidos de lo público referidos a la pluralidad y a la producción de bienes públicos, mereciendo, por tanto, un trato preferente al momento de llevar a cabo políticas públicas en educación.

Como se señaló, de acuerdo al uso de lo público como pluralidad, la universidad pública es aquella que dispone un ámbito - una esfera- en la cual se promueve el intercambio comunicativo bajo el modo de ejercicio de la razón pública. Allí, se manifiestan distintas posiciones y puntos de vista de sujetos que son tratados como iguales. La función de diversificación de las élites, asociada a la universidad moderna ${ }^{77}$, puede reconducirse hacia esta forma de comprensión de esa institución; también la producción de conocimiento. Según esta pretensión, la universidad pública promovería un modelo deliberativo basado en una especial disposición moral, a saber, la de "ajustar las decisiones a un ejercicio libre y adulto de la razón en las relaciones con nuestros semejantes, disposición que (...) implica necesariamente la disposición a dirimir las diferencias según la razón libre y no según la imposición"78. Por su parte, conforme a la concepción de la universidad pública creadora de bienes públicos, las instituciones educativas de la Administración generarían productos respecto a los cuales todos los ciudadanos participan en el mismo grado.

Si en estos dos sentidos de lo público yace el rasero para medir lo público de la universidad, la vinculación jurídica con la Administración del Estado deja de ser un asunto relevante, porque, como se señaló, la forma jurídica estatal solo asegura eso: forma jurídica estatal. Salvo cuando la regulación esté destinada a la implementación de un espacio institucional de permanente ejercicio de la razón pública en un entorno de pluralidad y

\footnotetext{
76 No se revisa aquí el segundo sentido de lo público expuesto arriba en 1.3 por trivial, en tanto, es evidente que cualquiera sea la universidad, su quehacer se lleva a cabo en un espacio de sociabilidad.

77 Brunner, José Joaquín; Peña, Carlos (2011) "La dialéctica público/privado entre el medioevo y la globalización”. En Brunner, José Joaquín; Peña, Carlos (editores): El conflicto de las universidades: entre lo público y lo privado. Santiago: Universidad Diego Portales, pp. 9-61, p. 55.

78 Garrido/Herrera/Svensson (2012) 67.
} 
asegurando la producción de bienes colectivos. Esta constatación permite, en primer término, detectar el verdadero alcance - y vicio- del argumento: tras la fachada de un uso meramente formal de lo público para aludir a lo estatal, en verdad se esconde la consideración de que en lo estatal yacen las virtudes de lo público desde un punto de vista sustancial. En segundo lugar, hace posible detectar que la publicidad como pluralidad y como producción de bienes públicos son exigencias cuya satisfacción puede verificarse en el mundo, es decir, se trata de una cuestión no necesaria, sino contingente. Esto significa que es perfectamente posible imaginar universidades de la Administración que no sean plurales ni generen bienes públicos de manera óptima. Por ello, quien sostiene que solo las universidades estatales son públicas - plurales y productoras de bienes públicos-, debe acreditar de manera empirica que ello es así y no solo suponerlo como virtudes implícitas en el uso de lo público como estatal.

La ausencia de necesidad entre universidad como órgano de la Administración del Estado y lo público en el uso relativo a la pluralidad, produce genuino escepticismo en algunos autores respecto a las consecuencias que se seguirían si todas las instituciones fueran estatales o bien no estatales. En efecto, se ha sostenido que "si todas las instituciones fueran estatales o todas privadas, el resultado probable sería, respectivamente, una hegemonía centro-izquierdista laica o una hegemonía Católica, cuando no un monopolio de una u otra corriente sobre la educación superior. En ambos casos, lo público como razón pública se vería menoscabado a favor de una inclinación hacia lógicas de intereses y poder"79. El recelo puede extenderse, asimismo, a la posibilidad de generación, a todo evento, de bienes públicos por parte de entidades administrativas de educación: es -como ya se señaló con Rawls- el legislador quien está encargado de configurar las condiciones para que los bienes públicos se produzcan. Ahora bien, como la vinculación entre lo público estatal y lo público plural o productor de bienes públicos es contingente, el argumento funciona también en dirección opuesta: es perfectamente posible imaginar instituciones constituidas conforme al derecho privado que, mediante una regulación -autoimpuesta incluso ${ }^{80}$ - y una disposición específicas, satisfagan las condiciones de publicidad como pluralidad, generando bienes públicos. Respecto a esto último, y solo a modo de ejemplo, la realidad da cuenta de que, en Chile, tratándose de indicadores de impacto y excelencia de la producción científica, entre los años 2008-2010, de los primeros 10 lugares, 6 instituciones son universidades privadas ${ }^{81}$. Esto permite

79 Garrido/HerRera/SVEnSSON (2012) 75.

80 Autorregulación basada en la garantía constitucional de autonomía de los grupos intermedios, de acuerdo al artículo $1^{\circ}$ inciso $3^{\circ}$ de la Constitución.

81 Se trata de las siguientes universidades: Pontificia Universidad Católica de Chile, Universidad de Concepción, Universidad Técnica Federico Santa María, Universidad Austral de Chi- 
demostrar la plausibilidad del argumento en lo que se refiere a los bienes públicos: la vinculación al Estado no es necesaria para producirlos.

Como consecuencia de lo anterior, las virtudes materiales de lo público no son susceptibles de ser reclamadas, bajo condición de exclusividad, por las universidades que forman parte de la Administración del Estado. No puede serlo, por lo demás, tomando en consideración que, en lo que atañe a la pluralidad, el ámbito administrativo estatal precisamente está diseñado para que sus funcionarios no ejerzan su razón pública o deliberativa. En efecto, lo que ocurre en estos órganos es exactamente al revés: están obligados al ejercicio de la razón privada en el ejercicio de sus labores, pues, sus integrantes tienen la calidad de funcionarios ${ }^{82}$, salvo que la regulación establezca otra $\cos ^{8}{ }^{83}$, como debería acontecer con las universidades. De ahí que, como se señaló, el ejercicio de la razón pública requiere también una regulación autoritativa que la haga posible. La universidad estatal, sin este elemento regulatorio, es puro poder burocratizado, carente del atributo de publicidad como pluralidad que en ella se pretende hallar. Esto significa que la institución universitaria administrativa no puede, en definitiva, autojustificarse como pública sin satisfacer la exigencia de pluralidad que no le es esencial. Lo propio acontece con la producción de bienes públicos.

le, Pontificia Universidad Católica de Valparaíso y Universidad Católica del Norte. Véase, al respecto, la Tabla 49. Indicadores básicos de las instituciones universitarias en CONICYT (2014) Principales indicadores cienciométricos de la actividad cientifica chilena 2012. Informe 2014: una mirada a 10 años. Madrid-Valparaíso: CONICYT, 308 pp., p. 151.

82 Vale la pena recordar aquí que uno de los principios estructurantes de la organización administrativa es precisamente el principio jerárquico, conforme al cual, la Administración del Estado se organiza bajo un régimen de supra e infra ordenación en que los servicios que se encuentran en posición jerárquica superior detentan facultades de dirección sobre aquellos que se hallan en gradas inferiores. Esta idea se refleja en el artículo $7^{\circ}$ de la LOCBGAE, el cual indica que los funcionarios de la Administración del Estado están afectos a un régimen jerarquizado y disciplinario. Al respecto, Poвlete, Julia (2014) Ley de Bases y Estatuto Administrativo. Santiago: Librotecnia, 452 pp., p. 34. En un sentido crítico, pero en sintonía con este juicio, León (2011) 321-329 afirma que las universidades estatales poseen una autonomía restringida.

83 En contra de la jurisprudencia de Constitucional, certeramente se ha sostenido que la autonomía de las universidades del Estado es puramente legal y no constitucional, pues, esta última solo es una garantía que cubre a grupos intermedios no estatales. Véase: NúŃEZ, Manuel (2007b) "Las universidades estatales y la construcción unitaria del principio de autonomía universitaria: ensayo de una crítica a la jurisprudencia constitucional chilena". Estudios Constitucionales, Año 5, No 2, pp. 223-249, pp. 225-230, y Ferrada, Juan Carlos (2001) "La autonomía universitaria y los recintos universitarios: algunas reflexiones críticas acerca del contenido de esta relación jurídica". Revista de Derecho Universidad de Concepción, No 209, Año LXIX, enero-junio, pp. 77-95, p. 82. Siendo esto así, ha de concluirse que el legislador es el encargado de configurar las características de las universidades estatales con el objeto de exorbitarlas a la lógica jerarquizada del Derecho Administrativo. 


\section{(2.4.) ACERCA DEL TRATO PREFERENTE}

Si la universidad de la Administración solo es pública en el sentido de que su forma jurídica está asociada al Estado, sin que de ello pueda desprenderse alguna virtud, y desmontada la idea de que solo la universidad de la Administración del Estado es necesariamente la universidad plural o productora en todo caso de bienes públicos - pues, como se señaló, las instituciones administrativas de educación superior no pueden reclamar más que contingentemente estos usos de lo público-, tampoco existe un argumento que necesariamente justifique la exigencia de un tratamiento preferente. Desde luego, al menos hay una dimensión en la que tiene sentido atender las específicas características de las universidades estatales: es evidente que si el Estado ha creado un órgano administrativo para cumplir con ciertas funciones, debe financiar su funcionamiento a través de la ley de presupuestos, asegurándose de que ellas puedan llevarse a cabo plenamente. Pero este es un estándar de idoneidad presupuestaria. Lo que no puede sostenerse es que sea correcto per se el otorgamiento de un trato preferente asociado a su carácter público que, como se vio, es contingente en sus versiones virtuosas.

Esa contingencia ha sido documentada por los especialistas, señalando que desde un punto de vista empírico es posible confirmar serios defectos en las universidades de la Administración, en virtud de lo cual abogan por severas transformaciones en el sistema de entidades estatales, lo cual requiere que "esas instituciones estén gobernadas por el Estado y no capturadas por sus corporaciones académicas, como desgraciadamente, ocurre en muchas de ellas; que las mejores cuenten con sistemas de acción afirmativa o de discriminación positiva a la hora de seleccionar a sus estudiantes, en vez de, como sucede hoy, reclutarlos mediante escalas ordinales de rendimiento que, sabemos, expresan diferencias socioeconómicas; que abandonen la presunción meritocrática, es decir, que se vuelvan más conscientes de los mecanismos mediante los cuales se distribuye el conocimiento y el poder (y eviten así algunas de ellas transformarse, por el mecanismo de selección usado, en las más selectivas socialmente de todas); y que, en fin, se resignen a que no todas las que actualmente existen, y ni siquiera la mayoría de ellas, merecen ese trato preferente en un sistema bien equilibrado" 84 .

El trato preferente, pues, es improcedente por la sola vinculación entre la universidad y la Administración y solo podría defenderse razonablemente previa realización de reformas regulatorias, cuyo objeto consista en convertirlas en verdaderas universidades públicas, esto es, asegurando la pluralidad, el libre desarrollo de la razón y la producción de bienes públi-

Brunner/Peña (2011) 57. 
cos. Pero esto significa, a su vez, que estos sentidos de lo público pueden hallarse en instituciones que no han sido constituidas por el Estado. Es difícil discutir, desde esta perspectiva, los aportes públicos a la educación superior de las universidades no estatales creadas antes de $1981^{85}$ y -salvo que el criterio cronológico sea relevante (que no lo es)- la contribución de varias instituciones creadas con posterioridad a esa fecha ${ }^{86}$. Esto es distinto de defender una equivalencia entre lo público y el mercado. En lugar de ello, se trata de vincular lo público a una específica regulación ${ }^{87}$ que configure las condiciones para que prestadores estatales y no estatales se conduzcan de modo deliberativo y generen bienes de provecho común.

\section{CONCLUSIONES}

1. En este texto, se ha analizado el concepto de lo público, basándose en ideas provenientes de la Teoría del Derecho, la Teoría Política y la Economía, bajo el supuesto de que existe una diversidad de usos que suelen confundirse. Esta es precisamente la situación de quienes consideran que solo son susceptibles de denominarse públicas aquellas universidades que forman parte del Estado.

2. El argumento conforme al cual solo las universidades estatales merecen ser denominadas públicas es un uso de lo público que solo da cuenta de que dichas entidades forman parte de los cuadros orgánicos de la Administración. Solo eso. Sin embargo, ese uso encubre un intento de atribuir a las universidades estatales ciertas virtudes, tales como que ellas serían necesariamente un entorno propicio para la deliberación o bien que siempre producirían bienes públicos.

3. Se ha mostrado en este texto que los dos últimos usos son contingentes al relacionárseles con la universidad estatal y que, sin una reforma regulatoria, no es posible asegurar que esas características se verifiquen en cualquier tipo de institución (estatal y no estatal). Por lo tanto, no existe

85 Este aserto puede comprobarse revisando los indicadores de las universidades privadas creadas antes de 1981, en http://redg9.cl/resumen-de-indicadores-de-la-universidades-de-redg9/ [fecha de visita 30 de noviembre de 2015].

86 Tratándose del alto impacto de las universidades privadas creadas luego de 1981, resulta paradigmático, en cuanto al diseño e implementación de políticas públicas, el caso de la reforma al proceso penal surgida en la Facultad de Derecho de la Universidad Diego Portales. Para una explicación de esta "muestra [de] que es posible emplear medios privados para la producción de iniciativas públicas de importancia”, véase VARGAS, Juan Enrique (2011) "Reforma procesal penal: el aporte de la Universidad Diego Portales". En Prieto, Alfredo et al.: El aporte de las universidades privadas al pais. Santiago: Libertad y Desarrollo, pp. 205-236, p. 207.

87 Atria (2014) 240 afirma sobre este punto que "[l]o razonable es decir que la conexión que importa es la que existe entre la función y el régimen. Si la función es pública, el régimen ha de ser el de lo público, con independencia del agente". 
sustento para la exigencia de trato preferente a las universidades de la Administración del Estado.

\section{BIBLIOGRAFÍA CITADA}

Arendt, Hannah (2005) La condición humana. Traducción de Ramón Gil Novales. Barcelona: Paidós, 368 pp.

Aristóteles (1989) Politica. Traducción de Julián Marías y María Araujo Fernández. Madrid: Centro de Estudios Constitucionales, 283 pp.

Atria, Fernando (2014) Derechos sociales y educación. Santiago: LOM Ediciones, 332 pp.

Atria, Fernando; Sanhueza, Claudia (2013) Propuesta de Gratuidad para la Educación Superior Chilena. Santiago: Instituto de Políticas Públicas UDP, 15 pp. Disponible en: http://www.politicaspublicas. udp.cl/publicaciones/detalle.tpl?id $=375$

Bachelet, Michelle (2013) Chile de Todos. Programa de Gobierno 20142018, 198 pp. Disponible en: http://michellebachelet.cl/programa/

Bоввіо, Norberto (2006) "La gran dicotomía: público/privado". En Bobbio, Norberto: Estado, gobierno y sociedad: por una teoría general de la politica. Traducción de José Fernandez Santillán. México: Fondo de Cultura Económica, pp. 11-38.

Boloña, Germán (2008) Organización Administrativa. Santiago LexisNexis, 417 pp.

Brunner, José Joaquín; Peña, Carlos (2011) "La dialéctica público/ privado entre el medioevo y la globalización". En Brunner, José Joaquín; Peña, Carlos (editores): El conflicto de las universidades: entre lo público y lo privado. Santiago: Universidad Diego Portales, pp. 9-61.

Brunner, José Joaquín; Peña, Carlos (editores) (2011) El conflicto de las Universidades: entre lo público y lo privado. Santiago: Universidad Diego Portales, 460 pp.

Confederación de Estudiantes de Chile (2011) Petitorio, 6 pp. Disponible en: http://www.fepucv.cl/wp-content/uploads/2012/05/ Petitorio-CONFECH-Final.pdf

Confederación de Estudiantes de Chile (2011b) Convocatoria movilización y paro nacional, 1 p. Disponible en: http://confech. wordpress.com/2011/05/03/convocatoria-12-mayo-por-larecuperacion-de-la-educacion-publica/

CONICYT (2014) Principales indicadores cienciométricos de la actividad cientifica chilena 2012. Informe 2014: una mirada a 10 años. MadridValparaíso: CONICYT, 308 pp.

Contraloría General de la República (2013) Financiamiento fiscal a la educación superior, 75 pp. Disponible en: http://www.contraloria. 
cl/NewPortal2/portal2/ShowProperty/BEA\%20Repository/Portal/ Bases/Contabilidad/Universidades_del_Estado/Estudios/2013/1.pdf Elias, Norbert (1989) El proceso de la civilización. Investigaciones sociogenéticas y psicogenéticas. Traducción de Ramón García Cotarelo. México: Fondo de Cultura Económica, 581 pp.

Elórtegui, Claudio (2014) "¿Trato preferente o justo en educación superior?”. En Diario El Mercurio, 30 de agosto de 2014. Disponible en: http://www.elmercurio.com/blogs/2014/08/30/24792/Tratopreferente-o-justo-en-educacion-superior.aspx

Eyzaguirre, Nicolás (2013) “¿Por qué creo en la universidad pública gratuita?”. En Diario El Mercurio, 29 de diciembre de 2013. Disponible en: http://www.elmercurio.com/ blogs/2013/12/29/18222/Por-que-creo-en-la-universidad-publicagratuita.aspx

FerradA, Juan Carlos (2001) "La autonomía universitaria y los recintos universitarios: algunas reflexiones críticas acerca del contenido de esta relación jurídica”. Revista de Derecho Universidad de Concepción, No 209, Año LXIX, enero-junio, pp. 77-95.

Figueroa, Rodrigo et al. (2014) "Castigo a universidades por no pertenecer al Estado". En Diario El Mercurio, 12 de abril de 2014. Disponible en: http://www.elmercurio.com/ blogs/2014/04/12/21006/Castigo-a-universidades-por-nopertenecer-al-Estado.aspx

Flores, Arturo et al. (2014) "No es posible hablar de discriminación", en Diario El Mercurio, 8 de noviembre de 2014. Disponible en: http:// www.elmercurio.com/blogs/2014/11/08/26698/No-es-posiblehablar-de-discriminacion.aspx

Garrido, Juan Manuel; Herrera, Hugo Eduardo; Svensson, Manfred (2012) La excepción universitaria. Reflexiones sobre la educación superior chilena. Santiago: Universidad Diego Portales, 107 pp., p. 63.

Garzón Valdés, Ernesto (1998) "Privacidad y publicidad". Doxa, N²1, Vol. 1, pp. 223-244.

Habermas, Jürgen (2000) Perfiles filosófico-políticos. Traducción de Manuel Jiménez Redondo. Madrid: Taurus, 424 pp.

Habermas, Jürgen (2009) Historia y crítica de la opinión pública. La transformación estructural de la vida pública. Traducción de Antonio Doménech. Barcelona: Gustavo Gili, 352 pp.

Iglesias, Juan (2007) Derecho Romano: Historia e Instituciones. Barcelona: Ariel, 496 pp.

Jiménez Redondo, Manuel (2002) Modernidad Terminable $e$ interminable: Ensayos sobre democracia y liberalismo. Santiago: Universidad Diego Portales-Universitaria, 212 pp. 
Justiniano (1889) Cuerpo del Derecho Civil Romano. Traducción de Ildefonso García del Corral. Barcelona: Jaime Molinas Editor (t. 1), $980 \mathrm{pp}$.

Kant, Emmanuel (2002) “¿Qué es la Ilustración?”. En Kant, Emmanuel, Filosofía de la historia. Traducción de Eugenio Ímaz. México: Fondo de Cultura Económica, pp. 25-37.

Kelsen, Hans (1941) La Teoría pura del derecho. Introducción a la problemática cientifica del derecho. Traducción de Jorge Tejerina. Buenos Aires: Losada, 213 pp.

Kelsen, Hans (1951) Teoría general del Estado. Traducción de Luis Legaz Lacambra. México: Editora Nacional S.A., 544 pp.

LeÓn, José Julio (2011) "El conflicto de las facultades desde una perspectiva jurídica: lo público y lo privado en el debate sobre la autonomía universitaria”. En Brunner, José Joaquín; Peña, Carlos (editores): El conflicto de las universidades: entre lo público y lo privado. Santiago: Universidad Diego Portales, pp. 299-330.

Marginson, Simon (2011) "Higher Education and Public Good". Higher Education Quarterly, Vol. 65, N 4, pp. 411-433.

Martínez Concha, Francisco (2014) "Universidad pública". En Diario El Mercurio, 4 de febrero de 2014. Disponible en: http://www. elmercurio.com/blogs/2014/02/04/19202/Universidad-publica.aspx

Mayol, Alberto (2013) "Brunner, Peña, Bachelet: la educación y la transmutación de lo público". En Diario El Mostrador, 17 de diciembre de 2013. Disponible en: http://www.elmostrador.cl/ noticias/opinion/2013/12/17/brunner-pena-bachelet-la-educacion-yla-transmutacion-de-lo-publico/

Mayol, Alberto (2014) "El público espacio en que no está Carlos Peña". En Diario El Mostrador, 24 de marzo de 2014. Disponible en: http://www.elmostrador.cl/noticias/opinion/2014/03/24/el-publicoespacio-en-que-no-esta-carlos-pena/

Montes, Fernando; Carbone, Ricardo (2013) "Universidad pública no estatal". En Diario El Mercurio, 12 de septiembre de 2013. Disponible en: http://www.elmercurio.com/ blogs/2013/09/12/15178/Universidad-publica-no-estatal.aspx

NúŃEZ, Manuel (2007a) "Autonomía y libertad de enseñanza en las universidades con ideario religioso. El caso de las universidades Católicas". En Núñez, Manuel (coordinador): Las Universidades Católicas. Estudios jurídicos y filosóficos sobre la educación superior Católica. Antofagasta: Ediciones Universitarias Universidad Católica del Norte, pp. 49-76.

NúŃEZ, Manuel (2007b) "Las universidades estatales y la construcción unitaria del principio de autonomía universitaria: ensayo de 
una crítica a la jurisprudencia constitucional chilena”. Estudios Constitucionales, Año 5, No 2, pp. 223-249.

Organisation for Economic Co-operation and Development (2004) OECD Handbook for Internationally Comparative Education Statistics: Concepts, Standards, Definitions and Classifications. Paris: OECD, $271 \mathrm{pp}$.

Peña, Carlos (2014) "La revolución blanda". En Diario El Mercurio, 5 de enero de 2014. Disponible en: http://www.elmercurio.com/ blogs/2014/01/05/18378/La-revolucion-blanda.aspx

Peña, Carlos (2014) "Lo público y las universidades". En Diario El Mercurio, 20 de marzo de 2014. Disponible en: http:// www.elmercurio.com/blogs/2014/03/20/20373/Lo-publico-y-lasuniversidades.aspx

PÉrez, Víctor (2014) "Presión por recursos fiscales". En Diario El Mercurio, 31 de enero de 2014. Disponible en: http://www. elmercurio.com/blogs/2014/01/31/19103/Presion-por-recursosfiscales.aspx

Poblete, Julia (2014) Ley de Bases y Estatuto Administrativo. Santiago: Librotecnia, $452 \mathrm{pp}$.

Rabotnikof, Nora (1998) “Público-Privado". Debate feminista, Año 9, Vol. 18, pp. 3-13.

Rawls, John (2002) Teoría de la Justicia. Traducción de María Dolores González Soler. México: Fondo de Cultura Económica, 549 pp.

Samuelson, Paul A. (1954) “The Pure Theory of Public Expenditure". The Review of Economics and Statistics, Vol. 36, No 4, pp. 387-389.

Samuelson, Paul A. (1955) "Diagrammatic Exposition of a Theory of Public Expenditure". The Review of Economics and Statistics, Vol. 37, No 4, pp. 350-356.

SÁnchez, Ignacio (2014) “El presupuesto sí discrimina”. En Diario El Mercurio, 9 de noviembre de 2014. Disponible en: http://www. elmercurio.com/blogs/2014/11/09/26741/El-presupuesto-sidiscrimina.aspx

Servicio de Información de Educación Superior (2015) Compendio Histórico de Educación Superior. Informe de evolución de la matrícula total (1983-2014). Disponible en: http://www.mifuturo.cl/index. php/estudios/estructura-compendio

Sото KLoss, Eduardo (2012) "Las personas jurídicas administrativas del Estado". En Soto Kloss, Eduardo: Derecho Administrativo Temas Fundamentales. Santiago: Abeledo Perrot, pp. 255-264.

Valle, Aldo (2014) "Lo público limita con lo privado". En Diario El Mercurio, 29 de marzo de 2014. Disponible en: http://www. elmercurio.com/blogs/2014/03/29/20633/Lo-publico-limita-con-loprivado.aspx 
VARgas, Juan Enrique (2011) "Reforma procesal penal: el aporte de la Universidad Diego Portales". En Prieto, Alfredo et al.: El aporte de las universidades privadas al pais. Santiago: Libertad y Desarrollo, pp. 205-236, p. 206.

Warren, Samuel; Brandeis, Louis (1980) “The Right to Privacy". Harvard Law Review, Vol. 4, N 5, pp. 193-220.

Weber, Max (2002) Economía y sociedad. Traducción de José Medina Echavarría. Madrid: Fondo de Cultura Económica, 1245 pp.

Weintraub, Jeff (1997) "The Theory and Politics of the Public/Private Distinction”. En Weintraub, Jeff; Kumar, Krishan (editores): Public and Private in Thought and Practice. Chicago: University of Chicago Press, pp. 1-42.

Zolezzi, Juan Manuel; De los Ríos, Danae (2008) “El futuro de las universidades estatales”. En Brunner, José Joaquín; Peña, Carlos (editores): Reforma de la educación superior. Santiago: Universidad Diego Portales, pp. 377-402.

\section{JURisprudenCiA CitadA}

Tribunal Constitucional. 5 de septiembre de 2006. Rol No 18922011. "Requerimiento de inaplicabilidad por inconstitucionalidad presentado por Víctor Pérez Vera, Rector de la Universidad de Chile, respecto de la parte final del inciso primero del artículo $2^{\circ}$ de la Ley 20.285 en el recurso de queja de que conoce la Corte Suprema, bajo el Rol N 9777-2010”. Disponible en: http://www. tribunalconstitucional.cl/wp/ver.php?id=2231

Contraloría General de la República. 18 de julio de 1990. Dictamen No 20.393.

Contraloría General de la República. 27 de diciembre de 2007. Dictamen No 59.048.

\section{NORMAS CITADAS}

Constitución Política de la República.

Decreto Ley No 3.541 del Ministerio de Educación Pública, de 12 de diciembre de 1980, que delega facultades que indica. Publicado en el Diario Oficial el 13 de diciembre de 1980.

Decreto con Fuerza de Ley No 1 del Ministerio de Educación, de 30 de diciembre de 1980, que fija normas sobre universidades. Publicado en el Diario Oficial el 3 de enero de 1981. 
Decreto con Fuerza de Ley $\mathrm{N}^{\circ} 2$ del Ministerio de Educación, de 30 de diciembre de 1980, que fija normas sobre universidades. Publicado en el Diario Oficial el 7 de enero de 1981.

Decreto con Fuerza de Ley $\mathrm{N}^{\circ} 2$ del Ministerio de Educación, de 4 de junio de 1985, que fija el texto coordinado, sistematizado y refundido del Estatuto Orgánico del Consejo de Rectores. Publicado en el Diario Oficial el 21 de enero de 1986.

Decreto con Fuerza de Ley No 1-19.653 del Ministerio Secretaría General de la Presidencia, de 13 de diciembre de 2000. Publicado en el Diario Oficial el 17 de noviembre de 2001, que fija texto refundido, coordinado y sistematizado de la Ley No 18.575, Orgánica Constitucional de Bases Generales de la Administración del Estado. 
